\title{
Teaching Effectiveness and Outcomes-Based Approach: Perceptions among Sub-Degree Teachers in Hong Kong
}

\author{
Jennifer Fung-Yee Lee and Ho-Yin Cheung
}

\begin{abstract}
Despite the wide adoption of outcomes-based approach (OBA) in local tertiary institution as a policy mandate, it remains questionable whether or not front-line teachers hold consistent conception of $\mathrm{OBA}$ as compared to that of the policy makers. By interviewing a group of teachers in the local sub-degree sector, we find that although teachers try to comply with OBA as an institutional policy, the special educational needs of sub-degree students have led to diverse views on the values of education, leading to differences in the interpretation of learning outcomes, teaching effectiveness, and OBA implementation. Implications of this diversity are discussed.
\end{abstract}

Index Terms-Outcomes-based approach, sub-degree sector, teaching effectiveness.

\section{INTRODUCTION}

The outcomes-based approach (OBA) of teaching and learning is thought by many as an effective way to assure high quality education especially in the post-secondary sector by better motivating students [1]. It also mandates a target-oriented approach of curriculum design and provides an evidence-based management system to assess the quality of the curriculum and the teaching, thus improving teaching effectiveness by holding the teachers more accountable to the outcomes of their teaching [2], [3].

While this is a very reasonable model from the point of view in management, there is no reason to suggest that this is the only possible model. This is especially plausible from the point of view of front-line teachers in the sub-degree sector, whose job nature is vastly different from that of the school administrators, policy makers, as well as their peers teaching undergraduate programmes. Teachers with different perceptions of teaching effectiveness may either disagree with the philosophy of OBA or have their own interpretation of OBA. This insight is important because, in terms of educational change, initiation and implementation are only part of the change process, whereas it is equally important to internalize the change into the institutional culture to make it sustainable in long term [4]. Ignoring this fact might easily reduce the efforts of OBA to a facade of compliance without bringing real enhancement to the quality of teaching and learning.

This qualitative study aims to solicit front-line teachers' views and understandings on teaching effectiveness and conception of OBA in the self-financing sub-degree institution. It is hoped that this would fill the gap between the educational policy and actual implementation of OBA.

Manuscript received March 10, 2014; revised May 15, 2014.

Jennifer Fung-Yee Lee is with the Community College, Lingnan University, Hong Kong (e-mail: jenlee@ln.edu.hk).

\section{BACKGROUND ON OBA AND TEACHING EFFECTIVENESS}

"You do what you say, you say what you do." This statement elegantly pinpoints the central philosophy of outcome-based curricular design, which signifies target-oriented approach of curriculum planning to emphasize what is learnt by the students instead of what is taught by the teachers. Under this philosophy, educators should define the explicit set of intended learning outcomes that graduates are expected to achieve after completion of the programme [1]. All the learning activities of the programme should be constructively aligned with the learning outcomes, while assessments are designed to measure the prescribed learning outcomes, usually in the form of criteria-referenced assessment (CRA) [5].

Those who take the positivistic worldview will find OBA a very straightforward approach of curricula design as it assumes an objective level of achievement of the students that can be defined, identified, measured and reported. It is no surprise if some teachers have already been using OBA implicitly in their teaching before 2005. This is especially plausible in some practically oriented subjects, which emphasize students' performance in various set tasks as the major evidence of learning. On the contrary, subjects with less clearly definable and measurable learning outcomes, e.g. philosophy, visual arts, literature, etc., may be less compatible with the OBA philosophy.

Under this target-oriented paradigm, it is intuitive to define teaching effectiveness in terms of how well a teacher helps the students achieve the learning outcomes. In fact, a number of authors are concerned about the measurement of teaching effectiveness in a scientific way, and all of them deliberately focus on the evidence showing the outcomes of teaching rather than the effort put in by the teachers. These measurements fall into two categories: indirect measurement of stakeholders' perception (rating) on teaching effectiveness, and the more direct measurement of students' learning outcome through assessment.

Lancaster [6] suggests that to measure teaching effectiveness is to consider how well a faculty member fulfills his obligation to the institution. He comes up with four measurement items: delayed student opinions, opinions of colleagues, achievement on examinations, and achievement in subsequent courses. The first item measures the perception of students on the teaching effectiveness of the teacher after the end of the course. The second item involves the peer evaluation by colleagues, which is also in the perception aspect. The third and fourth items are more concrete, as they attempt to measure the outcomes of learning 
of the students as demonstration in the final examination and subsequent courses.

Researchers have diverse views on the use of student rating to evaluate teaching effectiveness. Some suggest that ratings of teaching effectiveness by students, colleagues, trained classroom raters, former students, etc. appear to be effective evaluation methods [7]. This approach is heavily criticized by some authors, however. Olivares [8], for example, argues that the use of student opinion in teaching evaluation puts academic control and authority in the hands of students and therefore should be avoided.

In principle, the delayed teaching evaluation addresses some of these critiques, as students are less affected by emotion associated with the course grade when they do the evaluation. However, it is practically too costly if not impossible to conduct such an evaluation. Peer teacher evaluation can be misleading too if the teachers who conduct the evaluation obtain some of his/her views from students. Even the teachers' own point of view may be biased since they do not normally attend the lessons of their peers. To sum up, these two items measure the students' and colleagues' perception on one's teaching effectiveness rather than the teaching effectiveness itself. The results can only serve as indirect evidence.

The students' achievements are potentially more directly related to learning outcomes. While the achievement in subsequent courses suffers from the same problem as the delayed student opinion approach, the achievement in examinations is a more practical way of measuring students' learning outcomes. Lancaster [6] suggests, though, that adjustments should be made to address the prior difference in students' achievements, goals, GPA, and in particular, the relation of the course to the student's major. Other suggestions include the use of teaching portfolios, classroom observations, and the scholarship activities of the teachers [9].

\section{BACKGROUND ON THE IMPLEMENTATION OF OBA IN LOCAL SUB-DEGREE SECTOR IN HONG KONG}

Sub-degree refers to the academic qualification designed to be one level lower than the undergraduate degree (UG) qualification. Under the Hong Kong Qualifications Framework (HKQF), both Associate Degree (AD) and Higher Diploma (HD) qualifications are classified under this category. AD aims to be more academically oriented, while HD has a heavier emphasis on vocational training. The authors' institution mainly offers full-time AD programmes.

OBA was officially introduced to the tertiary institutions in Hong Kong by the University Grant's Committee (UGC), the local funding body of publicly funded institutions, in 2005 [10]. Although most of the local sub-degree providers were self-financing, leaving them unaffected by UGC's funding consideration, the subsequent rollout of the aforesaid HKQF forced tertiary institutions, including self-financing ones, to adopt OBA into their curricula in order to be registered into HKQF so that their awards would be recognized by other institutions.

The first author's institution began to incorporate OBA into its curricula in 2006. The change was mandated top-down by the senior management in the form of modified quality assurance (QA) requirements, while programme leaders were supposed to serve as change agents. Teachers were requested to adopt OBA in their teaching. To develop their capacity for the change, teachers were encouraged or sometimes mandated to attend OBA seminars and symposiums held by UGC and other institutions, while internal workshops were conducted to introduce the notions of OBA to all the teachers and the senior administrative staffs.

Teachers were requested to adopt OBA in their teaching. To develop their capacity for the change, teachers were encouraged or sometimes mandated to attend OBA seminars and symposiums held by UGC and other institutions, while internal workshops were conducted to introduce the notions of OBA to all the teachers and the senior administrative staffs.

\section{Methodology}

Seven outstanding teacher awardees were selected among the different disciplines in a local sub-degree institution for an in-depth interview. Interview provides a platform for the interviewer and interviewee in expressing their views, their interpretation of the world and therefore it's not merely a collection of data about life but it is part of life. This research interview also aspires to serve a few purposes [11]. First of all, we would like to know what is "inside a person's head" that is knowledge the participant has in a particular issue or concept. Secondly, what a person likes or dislikes which is the values and preference of this issue. Lastly, what are the attitudes and beliefs (i.e. what the participant thinks about it)

\section{A. Participants and Interview}

Seven awardees of the "Outstanding Teacher Award" were selected for this in-depth studies and each was interviewed for approximate an hour by the project leader with the assistance of the project officer. The interview mainly divided into two parts while the first part focus on the discussion on the teaching effectiveness, and the second part on the adoption or philosophy of outcome-based education.

\section{B. Background of the Participants}

Different institutions may use various schemes in recognizing teachers' performance. One of the most common types is the "Outstanding Teacher Award Scheme". In the institution the researchers served, the scheme commenced in 2005 and awards 1-2 individuals who has outstanding performance in teaching and related areas. The assessment criterion are $70 \%$ in teaching (course and teaching evaluation, students' written comments and teaching philosophy) and $30 \%$ in services (to the College, the University and the local community). While having nominations from students and teaching counterparts, the panel will normally select one teacher for the "Outstanding Teacher Award". The panel also made recommendations for the "Certificate of Merit" if the second best candidate is identified during the selection process.

\section{Teaching Experience and Expertise}

As most of the self-financing institutions only admitted 
their first cohorts of Associate Degree students in 2000, the participants in this study reflected a substantial teaching experience in the sector, ranging from 4 to 12 years with the mean of 8.3 years. In respect to their expertise, over half of them teach language or language-related subjects. This high proportion may relate to the component of generic subjects $(60 \%)$ in the Associate Degree curriculum mandated by the Education Bureau.

The profiles of the teachers are summarized in the Table I:

TABLE I: PROFILES OF TEACHERS INTERVIEWED IN THE STUDY

\begin{tabular}{|c|c|c|}
\hline $\begin{array}{l}\text { Outstanding } \\
\text { Teacher } \\
\text { Awardee }\end{array}$ & Subject Area & $\begin{array}{c}\text { Years of Full-time } \\
\text { Teaching } \\
\text { Experience in } \\
\text { sub-degree sector }\end{array}$ \\
\hline 1. & $\begin{array}{c}\text { Information Literacy, } \\
\text { Mathematics and Business }\end{array}$ & 8 \\
\hline 2. & $\begin{array}{c}\text { Information Literacy, } \\
\text { Mathematics, Statistics and } \\
\text { Business } \\
\end{array}$ & 9 \\
\hline 3. & $\begin{array}{c}\text { Putonghua, Chinese languages } \\
\text { and Literature }\end{array}$ & 10 \\
\hline 4. & Putonghua, Chinese languages & 8 \\
\hline 5. & $\begin{array}{c}\text { Putonghua, Chinese languages } \\
\text { and Literature }\end{array}$ & 8 \\
\hline 6. & $\begin{array}{c}\text { Putonghua, Chinese languages } \\
\text { and Literature }\end{array}$ & 3 \\
\hline 7. & English languages & 12 \\
\hline
\end{tabular}

The interviews employed the semi-structured method or Interview Guide Approach [12] with a few key questions followed by open-end theme questions for discussions.

\section{Theme Questions - Related to Conception of Teaching Effectiveness}

\section{1) Structured questions}

1) How long have you served in the teaching profession?

2) What are the levels and subjects you teach/have taught?

\section{2) Theme questions for discussions}

1) How do you define teaching effectiveness?

2) As an Outstanding Teacher, do you find any difference between "Outstanding Teacher" and "Effective Teacher"? (If so, what are they?)

3) Can you name someone whom you think is an effective or outstanding teacher? What are the key characteristics of these teachers?

\section{E. Theme Questions - Related to the Adoption of $O B A$}

\section{1) Structured questions}

Is there any change in your teaching pedagogy after the introduction of OBA to the College? How far do you think OBA enhances the teaching effectiveness?

\section{2) Theme questions for discussions}

1) (To assess if the participate is an $O B A$ adaptor/Non-adaptor/partial-adaptor) - How do you assess your students? Do you have a reference table of each learning outcome that address to particular questions or assignment? Do you use rubrics in accessing students' assignments?

2) Do you think OBA should/could be adopted in courses of different programmes/disciplines?

To ensure the standardization or stimulus equivalence [13] on the understanding of interview questions for each participant, we provide the Table II with three key differences between traditional approach to teaching and OBA to teaching before the interview.

TABLE II: THREE KEY DIFFERENCES BETWEEN TRADITIONAL APPROACH TO TEACHING AND OBA TO TEACHING

\begin{tabular}{cccc}
\hline No & Areas & $\begin{array}{c}\text { Traditional } \\
\text { Approach }\end{array}$ & $\begin{array}{c}\text { Outcome-based } \\
\text { Approach }\end{array}$ \\
\hline 1 & $\begin{array}{c}\text { Learning } \\
\text { goals/outcomes }\end{array}$ & $\begin{array}{c}\text { Not clearly stated in } \\
\text { the course }\end{array}$ & $\begin{array}{c}\text { Open and clearly stated } \\
\text { in the course }\end{array}$ \\
\hline 2 & $\begin{array}{c}\text { Assessment } \\
\text { Objectives }\end{array}$ & Mastery of content & $\begin{array}{c}\text { Attainment of learning } \\
\text { outcomes }\end{array}$ \\
\hline 3 & $\begin{array}{c}\text { Assessment } \\
\text { Criteria }\end{array}$ & $\begin{array}{c}\text { Norm-referencing- } \\
\text { Grade based on a } \\
\text { normal distribution } \\
\text { curve }\end{array}$ & $\begin{array}{c}\text { Criterion-referencing- } \\
\text { Grade based on the } \\
\text { attainment of learning } \\
\text { outcomes specified in } \\
\text { the course }\end{array}$ \\
\hline
\end{tabular}

\section{FINDINGS}

\section{A. Conception of Teaching Effectiveness}

The study shows interesting difference between the conception of teaching effectiveness of our teachers and that appeared in the literature. While OBA advocates emphasize concrete evidence on the outcomes / outputs of teaching and learning, our teachers put an equal, if not heavier, emphasis on the inputs. For example, (Teacher \#6) mentioned that effective teachers are those who "have comprehensive pedagogical and content knowledge" and are "able to accurately demonstrate knowledge of the subject content". Another teacher (Teacher \#7) regarded "preparedness" and the number of hours a teacher is willing to spend outside classroom teaching as the criteria for an "effective teacher". None of them mentioned the course and teaching evaluation or any instrument that provides feedback of their teachings as a measurement of teaching effectiveness. In other words, this group of teachers apparently does not take the evaluative approach in accessing their effectiveness.

Even when outcomes are concerned, most of the madopt a much boarder definition of learning outcomes than those written in the syllabus. One teacher expressed that "teaching is not transmitting knowledge for students to learn what teacher knows, but to move students to enquire what they don't know yet" (Teacher 1).

Other teachers also define their teaching objectives as to "stimulate students interests to learn" (Teacher 2), "bring satisfaction to students" (Teacher 3), "care, nurture and develop minds and talents to students and foster students' whole person development" (Teacher 4), and "foster student's reflection" (Teacher 5). In other words, they refuse to limit their role to an instructor merely delivering subject knowledge, but also as a mentor of the students to take care of their whole-person development, and to inspire the students to further pursue on a subject area.

\section{B. Understanding and Mis-Understanding of $O B A$}

Most of the teachers interviewed are familiar with the underpinning principle of OBA. Nearly all could relate it to 
the assessments. Some of them mentioned using rubrics to guide their marking of assessments. One teacher (Teacher 1) said, "I use rubrics for various kinds of assessment (such as exam papers, case studies, essay reports...etc.)"

Some agreed that OBA facilitates better alignment for team teaching. For example, (Teacher 5) said, "Since all the learning outcomes are listed out clearly in each of the course syllabus under OBA, it strengthens the understandings of course objectives for new front-line teachers so as to help them deliver the content during the lesson comprehensibly."

Nevertheless, not all of them actually tapped into the core essence of OBA in practice. For example, (Teacher 7), who mentioned that she has adopted OBA in her courses, used "objectives" to refer to "outcomes" throughout the interview. She also seemed confused about "mastery of content" with "achievement of outcomes". Moreover, she expressed her concern that teachers were required to achieve outcomes (objectives) not only in the cognitive domain, but also in affective domain. Apparently, she was taking the boarder definition of learning outcomes as depicted in the previous section and worried that the College was using the OBA system to track their achievements in accomplishing these learning outcomes in her students. Or teachers would like to show their supports to the Policy and therefore replied their efforts in the course of delivery like "OBA widens my horizon in course preparation......I use different methods in teaching my students and would embedded the current news when explaining the key concepts." (Teacher 4) instead of focusing on the whether the learning activities are aligned with the course intended learning outcomes.

It was observed that the two teachers teaching business courses are more familiar with the essences of OBA. For example, (Teacher 2) mentioned that before the implementation of OBA, he tends to assess students' performance based on the course syllabus and course content. Now, he tends to assess students' performance based on the measurable learning outcomes. They could relate the key characteristics and how the approaches operate in the teaching and course delivery context.

To remark, while teachers might have different levels of understanding on OBA, nearly all of them indicated compliance to the pedagogy. No any respondent objected to have learning outcomes or measurement of learning outcomes be stated clearly in the course syllabus.

\section{Influences of OBA on Teaching Practices}

Over half of the respondents reflected that OBA did not really alter their teaching practices. (Teacher 7) said, "There is no change in my teaching (both teaching skills and teaching method) under the implementation of $O B A$." (Teachers 5) and (Teacher 6) stated explicitly that OBA brings no difference to her teaching but merely on the documentation. (Teacher 3)

Those teachers who indicated that OBA has altered their teaching practices are mainly related to the use of rubrics in grading assessments. As (Teacher 2) put it, "I didn't apply $O B A$ in my teaching and therefore it didn't affect my teaching much. However, I do use learning outcomes to assess students' performance...... fully implement $O B A$ in my recent teaching as it's a bias-free method for assessing students' performance without projecting their subjective opinions (such as essay reports, group projects, presentation...etc.)."'He thinks that teachers used to rate students' performance by their overall impression before adopting OBA.

To summarize, despite the fact that the teachers interviewed are well recognized by the students and their fellow colleagues as outstanding teachers, their understanding, acceptance and adoption of OBA are fairly limited according to our qualitative data presented above. They only partially agree with the philosophy of OBA as a target-oriented, evidence-based methodology to achieve a restricted set of learning outcomes in the students. Rather, they view themselves as both instructors and mentors, taking care of not only the student's academic knowledge but also their whole-person development. Since the latter is difficult to define and measure under the OBA framework, they put more emphasis on the input rather than output of teaching as a measurement of teaching effectiveness.

\section{DiSCUSSION AND CONCLUSION}

It is evident from our interviews that the participants have very different conception of both OBA and teaching effectiveness as compared to the literature. Students' rating/evaluation or assessments are not the components in their conception of effectiveness. They take aspiration on learning attitudes and identity development as a crucial part of teaching effectiveness. This conception of teaching effectiveness is not difficult to comprehend. Both the general public and even students themselves generally perceived people attending sub-degree programmes mediocre and even week in language proficiency and abilities. (Survey on Opinions of Employers on Major Aspects of Performance of Sub-degree Graduates in Year 2006)

This leads to a discussion on how we should perceive the value of education and the controversial discussion on the accountability on the provision of education. The outcomes-based approach, even with the delayed evaluation as mentioned before, invariably measures only those relatively short-term learning outcomes that are measureable by available assessment instruments. To regard OBA as an adequate model of teaching and learning is to suggest that all the important outcomes of education can be and can only be objectively measured in short-term so that teachers can be held accountable for the results of these measurements. This is not plausible in the case of sub-degree students, who seem to need intensive mentorship in their life journey in addition to subject knowledge. This would not dis-merit OBA as a quality assurance mechanism on some of the key learning outcomes of education, but it prompts us to rethink the difference in the educational needs between sub-degree and undergraduate students beyond academic knowledge delivery. Should the measurement of learning or accountability on the provision of education be more important than the making the students become a better self? If not, should aspiration on personal learning and development be a mandatory part in the measurement of teaching effectiveness? These questions deserve further reflection. 


\section{REFERENCES}

[1] W. G. Spady, "Outcome-Based education: Critical issues and answers," American Association of School Administrators, 1994.

[2] O. Au and R. Kwan, "Experience on outcome-based teaching and learning," in F. Wang, J. Fong, L. Zhang, and V. Lee, eds., Hybrid Learning and Education, 2009, pp. 133-139.

[3] P. Ewell, "To capture the ineffable: New forms of assessment in higher education," Review of Research in Education, vol. 17, pp. 75-125, 1991.

[4] M. Fullan, The New Meaning of Educational Change, $4^{\text {th }}$ ed., Oxon: Routledge, 2007.

[5] D. R. Sadler, "Interpretations of criteria-based assessment and grading in higher education," Assessment and Evaluation in Higher Education, vol. 30, no. 2, pp. 175-194, 2005.

[6] O. E. Lancaster, "Measuring Teaching Effectiveness," IEEE Transactions on Education, vol. 16, no. 3, pp. 138-142, 1973.

[7] G. S. Howard, C. G. Conway, and S. E. Maxwell, "Construct validity of measures of college teaching effectiveness," Journal of Educational Psychology, vol. 77, no. 2, pp. 187-196, 1985.

[8] O. J. Olivares, "A conceptual and analytic critique of student ratings of teachers in the usa with implications for teacher effectiveness and student learning," Teaching in Higher Education, vol. 8, no. 2, pp. 233-245, 2003

[9] L. P. Shao, L. P. Anderson, and M. Newsome, "Evaluating teaching effectiveness: Where we are and where we should be," Assessment \& Evaluation in Higher Education, vol. 32, no. 3, pp. 355-371, 2007.

[10] M. V. Stone. (2005). Opening remarks for the symposium on outcome-based approach to teaching, learning and assessment in higher education: International perspectives. UGC. [Online]. Available: http://www.ugc.edu.hk/eng/ugc/publication/speech/2005/sp171205.ht $\mathrm{m}$

[11] B. W. Tuckman, Conducting Educational Research, New York: Harcourt Brace Jovanovich, 1972.

[12] M. Q. Patton, Qualitative Evaluation Methods, Beverly Hills: Sage Publications, 1980.

[13] A. Oppenheim, Questionnaire Design, Interviewing and Attitude Measurement, London, 1992.

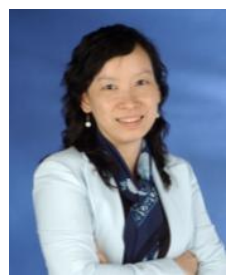

Jennifer Fung-Yee Lee received her first degree in business administration. She then pursued her MEd in psychology of classroom learning from the University of Hong Kong.

She serves the higher education sector in various capacities for close to 20 years. She joined Lingnan University in 1996 first as a researcher and then as an officer in managing research and staff development grants. She started her teaching career in psychology of learning in 2001 and became the first batch of teaching staff in the Associate Degree/Foundation Diploma programs in Hong Kong. With her passion and commitment in quality teaching, she received the first Outstanding Teacher Award of the College in 2005-6. She is now the Senior College Lecturer at the Community College at Lingnan University. Other than her teaching duties, she also leads HK\$6.6 million government-funded projects in enhancing teaching and learning in the sub-degree sector.

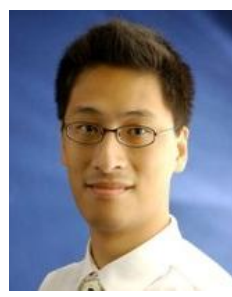

H. Y. Cheung received his B.Sc. and MPhil. in physics from the Hong Kong University of Science and Technology (HKUST), Hong Kong, China in 1999 and 2001 respectively. His research focus was mathematical modeling and scientific computation in the study of nanomaterials.

After graduation, he worked in the field of evolutionary algorithm research for one and a half years at Lingnan University, Hong Kong, China. He then served at the Community College at Lingnan University for the following nine years, working both as a teacher in science, mathematics, statistics, and ICT, and as a school administrator. Recently, he has changed his career to educational research. He is currently working at the Hong Kong Institute of Education (HKIEd), Hong Kong, China as a researcher. He is also pursuing his Ed.D., study at University of Bristol, UK. His research interest includes outcomes-based teaching and learning (OBTL), learning approaches, technology acceptance, flipped classroom, blended learning, and ICT in education in general. 